\section{Carat Yellow Gold Alloys with Increased Hardness}

\section{Rainer Süss, Elma van der Lingen and Lizelle Glaner}

Physical Metallurgy Division, Mintek, Private Bag X3015, Randburg 2125, South Africa.

e-mail: rainers@mintek.co.za

\section{Madeleine du Toit}

Department of Materials Science and Metallurgical Engineering, University of Pretoria, South Africa.

\section{Abstract}

An investigation was carried out by Mintek to examine the influence of a range of alloying additions (titanium, vanadium, chromium, molybdenum, cobalt, zirconium, boron, aluminium, silicon, zinc, platinum, palladium, rhodium, iridium and ruthenium) on the formability, hardenability and colour of 18 carat gold alloys. This paper provides chemical formulae for yellow 18 carat gold alloys that have hardnesses which are higher than the hardnesses of the corresponding conventional 18 carat alloys, in particular in excess of $300 \mathrm{HV}$, but with colours similar to conventional 18 carat gold. A preparation method for the alloys will also be described, which includes the steps of melting, annealing, quenching, cold working and age hardening.

\section{Introduction}

Why a harder 18 carat gold?

The gold alloys used in Europe for jewellery purposes are primarily 18 carat. This applies particularly to Italy, which still remains at the forefront of the gold jewellery industry, using more than 500 tonnes of gold per annum (1). The standard or conventional 18 carat gold - 75Au-12.5Ag-12.5Cu (weight per cent) - is a very popular alloy, lending itself well to cold working as well as machining in the hardened state. The maximum hardness that can be obtained in the alloy through a combination of heat treatment and cold working, is approximately $290 \mathrm{HV}$ (Hardness Vickers)(2).

In the watch industry, an even harder alloy (in excess of $300 \mathrm{HV}$ ) is desirable, since it would simplify the final machining of watch cases and could reduce the wear of the final product. Considering that the fabrication of carat gold jewellery in Switzerland (more than 45 tonnes per annum in 1999) (1) is dominated by the manufacture of gold watches, a considerable market for a hard 18 carat gold alloy is foreseen. A harder yellow 18 carat alloy could also find application in the production of clasps, collars, bracelets and watch straps. In the latter field of application, conventional 18 carat white gold alloys, which are electroplated with yellow gold, are mainly used. Due to European legislation limiting the use of nickel-containing white gold alloys, a need exists for high-strength 18 carat yellow gold alloys for use in high-strength applications. There could even be specialised non-jewellery related applications, such as pens.

\section{How is hardening obtained in conventional} 18 carat gold?

The Au-Ag-Cu system is the basis of the most common gold jewellery and dental alloys used today and dates back several millennia. Conventional 18 carat alloys are no exception. As a rule, pink or red 18 carat alloys are harder than yellow or

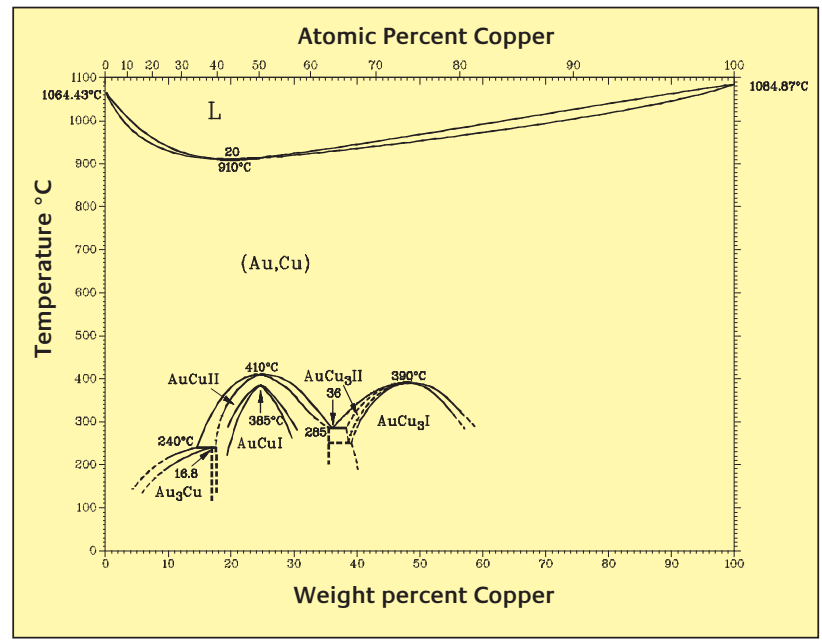

Figure 1

The Au-Cu binary alloy phase diagram (4) 
green ones, due to their higher Cu/Ag ratio. Copper is more effective in solid solution hardening because its atomic size difference with $\mathrm{Au}$ is much higher compared to that of Ag.

Extended solid solution hardening is, however, not the main reason why 18 carat alloys are harder than higher carat alloys. In 18 carat alloys an interesting hardening mechanism plays a role, facilitated by the Au-Cu system (3). In Au-Cu alloys, $\mathrm{Cu}$ can substitute in the solid phase for $\mathrm{Au}$ at all concentrations above a temperature of about $410^{\circ} \mathrm{C}$ (Figure 1). Below this temperature, one of two ordered compounds can form.

These ordered solid solutions (AuCul and AuCull) that form during ageing at lower temperatures are ordered structures in which the gold and copper atoms occupy specific sites in the crystal lattice (rather than at random, as is the case in ordinary solid solutions). Ordering in the AuCu region causes changes in the crystal structure and considerable strain develops in the surrounding matrix, resulting in hardening of the alloy. The transformation from disordered face centred cubic (fcc) AuCu to ordered AuCu in an 18 carat alloy has two definite forms, with face centred tetragonal AuCul being stable below $385^{\circ} \mathrm{C}$ and orthorhombic AuCull between $385^{\circ} \mathrm{C}$ and $410^{\circ} \mathrm{C}$. This transformation occurs during slow cooling, or by quenching from above $410^{\circ} \mathrm{C}$ and subsequent ageing in the $150-300^{\circ} \mathrm{C}$ range. Schematic representations of the different AuCu structures are given in Figure 2.

The Au-Cu system's ordering regions ( $\mathrm{AuCu}$ and $\mathrm{AuCu}_{3}$ ) also extend into the ternary Au-Ag-Cu system (5) (although ordering in the $\mathrm{AuCu}_{3}$ region (Figure 1) has relatively little effect on the development of hardness during annealing of Au-Cu alloys, as the ordering involves no structural and negligible dimensional changes.) These ordered phases, depending on their size and distribution, can therefore effect considerable strengthening in 18 carat Au-Ag-Cu gold alloys

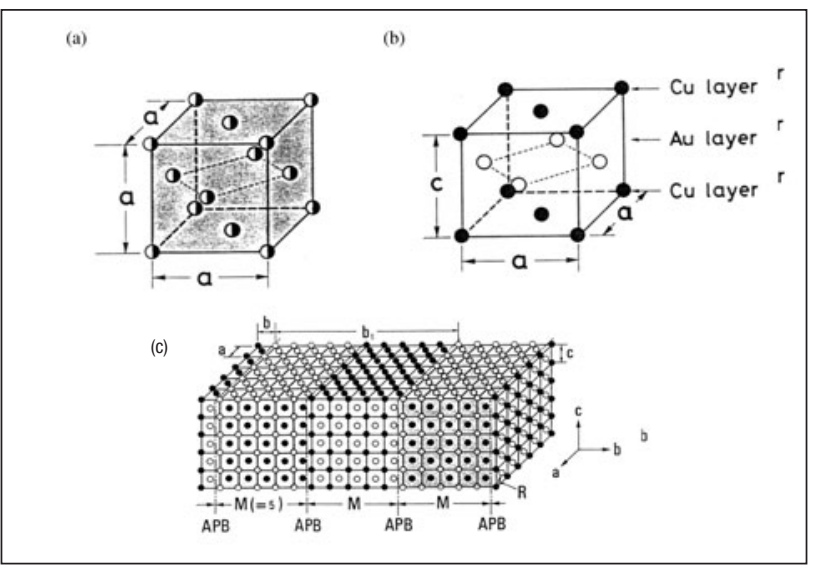

\section{Figure 2}

Schematic representations of the AuCu superlattice, showing unit cells of (a) the disordered f.c.c. structure, (b) the ordered f.c.t. AuCul structure, and (c) the orthorhombic AuCull structure (5). Open and solid circles indicate the gold and copper atoms, respectively

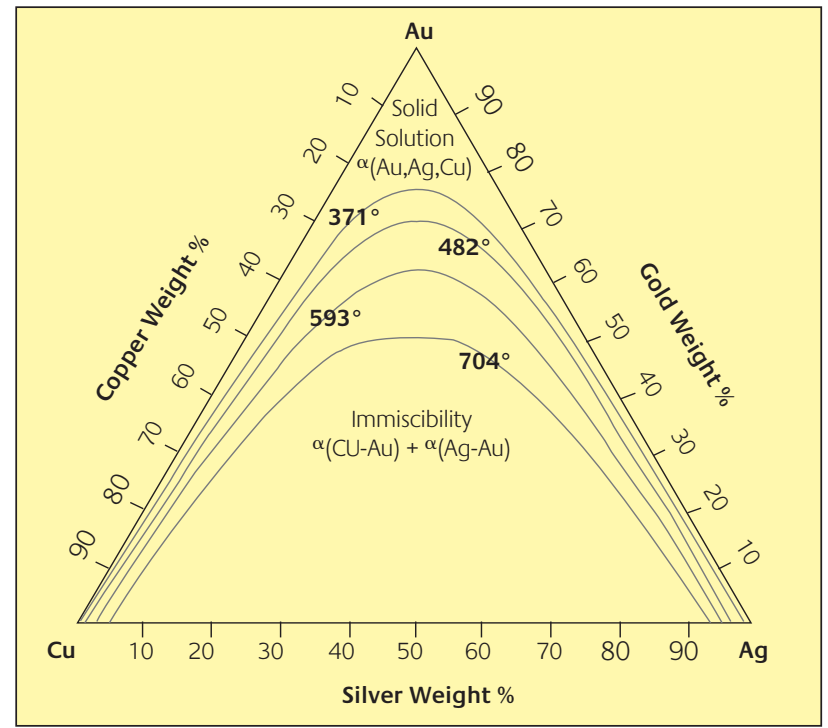

Figure 3

Some isothermal solid-state boundaries of the immiscibility field projected on the room temperature plane of the Au-Ag-Cu ternary phase diagram of (6)

through so-called order-disorder hardening.

The second mechanism of hardening that can play a role in 18 carat Au-Ag-Cu alloys is precipitation hardening, because the two phase region in the $\mathrm{Cu}-\mathrm{Ag}$ system with limited solid solubility on either side extends into the ternary phase diagram as shown in Figure 3.

This complicates matters actually, because it had been shown that hardening is achieved by a combination of precipitation hardening and ordering (5). Studying the isopleth of the ternary system at 75 wt\% Au (Figure 4), agehardening can be obtained at copper concentrations between 5 and 22.5 wt per cent and silver contents between 20 and 2.5 wt per cent (6). This in itself is, however, not sufficient to obtain hardnesses in excess of $300 \mathrm{HV}$.

\section{How can the hardness of 18 carat gold be increased?} In trying to harden any alloy, one is bound by metallurgical principles, and excluding cold deformation, additional strengthening in the Au-Ag-Cu system can be obtained by one or more of the following mechanisms:

- solid solution strengthening,

- hardening by grain refining, and

- usually more importantly, hardening by precipitation of a second phase during ageing.

These hardening mechanisms could all be facilitated by the addition of one or more alloying elements, either through conventional alloying (>0.5 wt\% alloying element) or microalloying (<0.5wt\%). A number of microalloyed 99.5 to 99.9 wt\% Au alloys had been developed over the years $(7,8,9)$. The low alloy content was designed to make these 


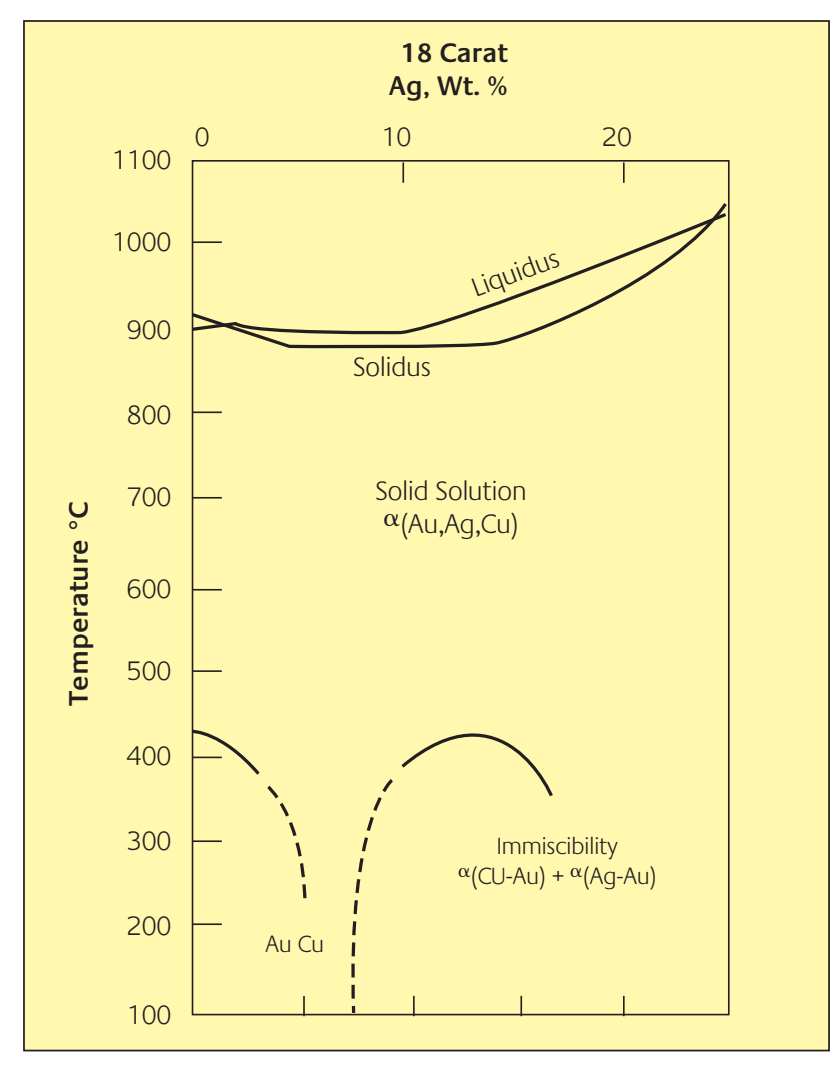

Figure 4

Isopleth at gold content 75 wt\% (18 carat) of the Au-Ag-Cu ternary phase diagram (6)

alloys hallmarkable as 24 ct gold for the jewellery industry. With 18 carat alloys this consideration is of course not a factor, and not only is one not restricted to microalloying in order to obtain the necessary age hardening, but one will probably find that a higher amount of alloying is necessary to obtain significant age hardening. In this investigation several alloying elements ( 0.5 wt.\% and above) were chosen and their effect on the alloy's colour, ductility and hardness was determined. This article reports on elements that had either beneficial or adverse effects on the alloy's properties. One needs to add that although this paper focuses on 18 carat alloys only, the same approach could be used for alloy development in lower or higher caratage, like 14 carat or 21/22 carat.

\section{Experimental procedure}

All alloys were prepared by melting the appropriate amounts of gold and alloying additions in a button arc furnace under an argon atmosphere, producing small samples weighing $3 \mathrm{~g}$ each. After solidification the samples were solution annealed for 30 minutes at various temperatures (see Tables 1 to 8 ) in order to fully homogenise the microstructure. This was followed by water quenching and thereafter the alloys were cold rolled, to achieve a reduction of between 50 and 60 per cent, using a jewellery mill. The alloys were then polished by buffing them on a jewellery buffing wheel. The alloy's colour was determined by a Pacific Scientific ClELab spectrophotometer. The cold rolled alloys were subsequently aged for up to 10 hours. Samples were removed from the furnace at 1 hour intervals to determine the hardness. The earlier the peak hardness could be obtained (preferably in 3 hours or less), the better. The hardness of the alloy was determined after each step (annealed, cold worked, ageing interval) using a macro Vickers hardness tester with a $10 \mathrm{~kg}$ load.

The following alloy properties of conventional 18 carat yellow gold (75Au-12.5Cu-12.5Ag) were used as benchmarks to improve on (2):

- Annealed @ 550 $\mathrm{C}, 30$ minutes: $150 \mathrm{HV}$

- 60\% Cold worked: $224 \mathrm{HV}$

- Aged @ 300, 5 hours: 287 HV

\section{The addition of $\mathrm{Co}$}

Co is already known to act as grain refiner, especially in the annealed and cold worked state (10). Grain refining has already been mentioned as a strengthening mechanism, but would never induce the hardening that was required in this investigation. However, according to the binary Au-Co alloy phase diagram (Figure 5), the addition of small amounts of Co could potentially induce a precipitation hardening reaction. A Co-rich $\epsilon$-Co phase will precipitate from metastable Au-rich Au-Co solid solutions during ageing at temperatures below $\sim 422^{\circ} \mathrm{C}$.

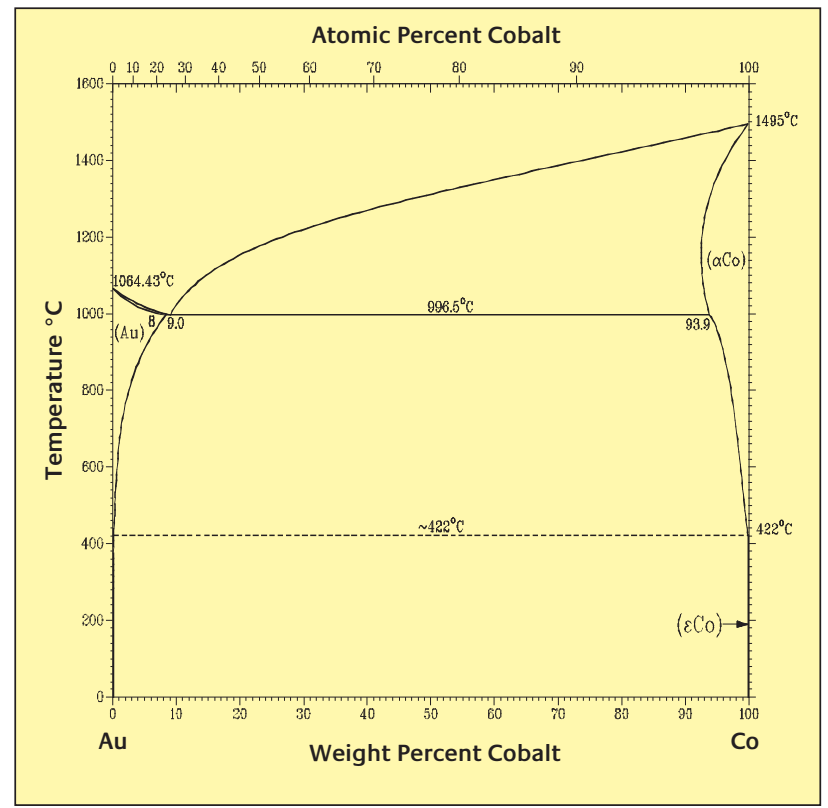

Figure 5

The Au-Co binary alloy phase diagram (4) 
Table 1

Hardnesses of Co-containing samples in different conditions

\begin{tabular}{|l|l|l|l}
\hline Alloy (wt\%) & Annealed @ 850 & $\mathbf{6 0 \%}$ Cold worked & Aged @ $\mathbf{3 0 0}{ }^{\circ} \mathbf{C}$ (peak hardness) \\
\hline $75 \mathrm{Au}-7 \mathrm{Cu}-13 \mathrm{Ag}-5 \mathrm{Co}$ & $128 \mathrm{HV}$ & $205 \mathrm{HV}$ & $232 \mathrm{HV}$ after 10 hours \\
\hline $75 \mathrm{Au}-12 \mathrm{Cu}-12 \mathrm{Ag}-1 \mathrm{Co}$ & $125 \mathrm{HV}$ & $239 \mathrm{HV}$ & $300 \mathrm{HV}$ after 2 hours \\
\hline $75 \mathrm{Au}-12.2 \mathrm{Cu}-12.2 \mathrm{Ag}-0.6 \mathrm{Co}$ & $121 \mathrm{HV}$ & $219 \mathrm{HV}$ & $265 \mathrm{HV}$ after 3 hours \\
\hline
\end{tabular}

* $50 \%$ cold worked

Table 2

Hardnesses of Ti-containing samples in different conditions

\begin{tabular}{|c|c|c|c|}
\hline Alloy (wt\%) & Annealed @ $850^{\circ} \mathrm{C}$ & $50 \%$ Cold worked & Aged @ $500^{\circ} \mathrm{C}$ (peak hardness) \\
\hline 75Au-12.5Cu-11.5Ag-1Ti & 159 HV & $245 \mathrm{HV}$ & $256 \mathrm{HV}$ after 1 hour \\
\hline 75Au-11.5Cu-11.5Ag-2Ti & $169 \mathrm{HV}$ & $247 \mathrm{HV}$ & 265 HV after $1 / 2$ hour \\
\hline
\end{tabular}

The first alloy in Table 1, however, shows that 5 wt\% Co gave the least amount of age hardening. Considering that pale yellow gold of composition 75Au-16Ag-9Cu only reaches a peak hardness of $170 \mathrm{HV}$ during ageing at $280^{\circ} \mathrm{C}$ (2), the Co addition did give substantial hardening (to $232 \mathrm{HV}$ ). However, the hardening that the Co induced was offset by the substantially reduced $\mathrm{Cu}$ content.

The loss of hardness due to reduced Cu content therefore had to be avoided. In the other two alloys the $\mathrm{Cu} / \mathrm{Ag}$ ratio was kept to 1:1 and much smaller amounts of Co additions were evaluated. The solubility of $\mathrm{Co}$ in gold is at low temperatures is low (even more so in 18 carat gold because of the silver content (11)), and only a concentration of Co exceeding its solubility in the alloy is necessary to induce fine precipitation.

This was proved to be the case. Co addition of 1 wt\% produced an alloy with very good ageing behaviour, better than the conventional 18 carat alloy. The $0.6 \%$ Co addition resulted in an alloy with a slightly better colour than the $1 \%$ addition, but the $300 \mathrm{HV}$ hardness obtained with the latter was much more promising, especially considering that the high hardness was reached within 2 hours' ageing. The alloy was very formable.

To illustrate the applicability of such an approach to other caratages, it can be noted that Co has indeed also been proven to be a very good additive in 22 carat gold to give it substantial hardening $(9,12)$.

\section{The addition of $\mathrm{Ti}$}

Ti was added in an attempt to utilise the $\mathrm{TiAu}_{4}$ precipitation reaction (Figure 6). This had already been demonstrated successfully in the development of 990 gold (13), where 1 wt.\% $\mathrm{Ti}$ in Au gives an aged hardness of $240 \mathrm{HV}$ in a cold worked sample. The effect of Ti additions to 18 carat gold is shown in Table 2. Once again the Cu/Ag ratio was kept close to $1: 1$ to avoid hardness loss due to reduced Cu content.

The hardnesses of the alloys were well below the required level of $300 \mathrm{HV}$ and the colour of the samples was very pale. The insignificant hardening being achieved could be the result of the solubility of $\mathrm{Ti}$ in Au being increased by $\mathrm{Cu}$ and/or Ag resulting in less precipitation, although not a lot is known about the phase relations in the quaternary system.

In order to increase the hardness Co was added and to improve the colour $\mathrm{Zn}$ was added and the gold content increased to $80 \mathrm{wt} \%$. From Table 3 one can see that a high hardness can be readily achieved by the Ti-Co combination, but the colour of the alloy remained pale. Furthermore, the formability of the alloy was also compromised. It was therefore concluded that $\mathrm{Ti}$ is not an acceptable alloying addition for hardening 18 carat gold.

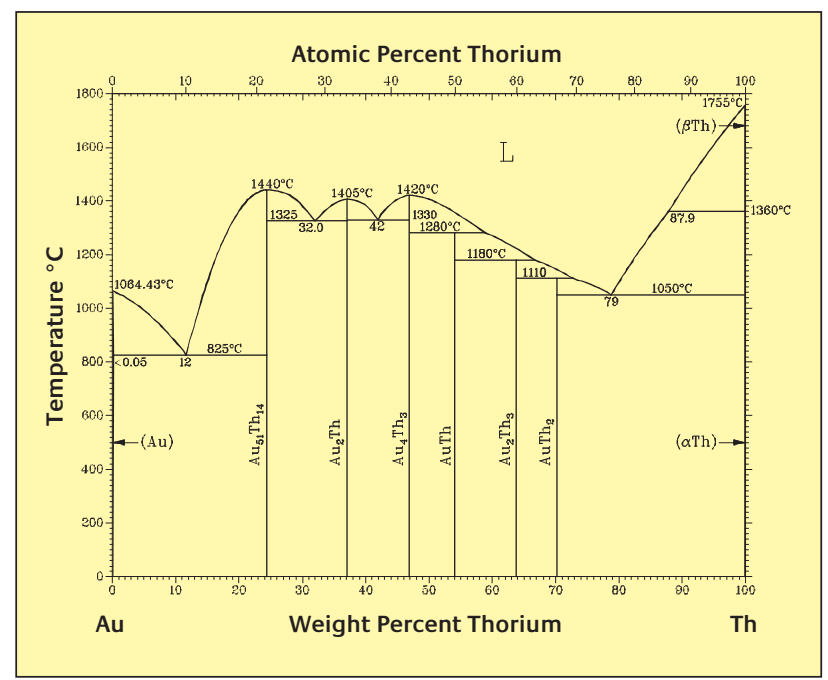

Figure 6

The Au-Ti binary alloy phase diagram (4) 
Table 3

Hardnesses of Ti-, Co- and Zn-containing sample in different conditions

\begin{tabular}{|c|c|c|c|}
\hline Alloy (wt\%) & Annealed @ $850^{\circ} \mathrm{C}$ & $50 \%$ Cold worked & Aged @ $500^{\circ} \mathrm{C}$ (peak hardness) \\
\hline $\begin{array}{l}\text { 80Au-6Cu-3.03Ag-3.47Zn- } \\
0.5 \mathrm{Co}-2 \mathrm{Ti}\end{array}$ & $205 \mathrm{HV}$ & $271 \mathrm{HV}$ & 322 HV after $1 / 2$ hour \\
\hline
\end{tabular}

\section{The addition of platinum group metals (PGMs)}

Platinum and palladium are often added to gold dental alloys. The addition of palladium or platinum to a $\mathrm{Au}-\mathrm{Ag}-\mathrm{Cu}$ ternary alloy results in a considerable increase in strength. The primary strengthening mechanism in the dental alloys is the disorder-order transformation, with any precipitation only playing a secondary role $(5,14,15)$. Pd additions to 18 carat gold had been thoroughly investigated in the past with the development of white gold and dental alloys, and was not considered in this investigation. The effect of Pt addition on 18 carat alloys was of greater interest, despite its high price.

Furthermore, very little is known about the influence of $\mathrm{Ru}, \mathrm{Rh}$ and Ir on the properties of carat gold alloys. Small amounts (<0.5 wt\%) are often added as grain refiners (11), but no information appeared to be available on the effects of higher levels, except that higher concentrations should be avoided because of the difficulty dissolving these elements in gold alloys (11). The solubility of these elements in gold is extremely limited (Figures 7-8); Ir and gold are not even soluble in the liquid state (4). One could expect precipitation at higher alloying levels.

Table 4 shows the compositions and properties of a first batch of experimental alloys containing Pt, Ru, Rh and Ir respectively. Note that the $\mathrm{Ru}, \mathrm{Rh}$ and Ir were all added in the form of a Cu-20 wt\% PGM master alloy to ensure even

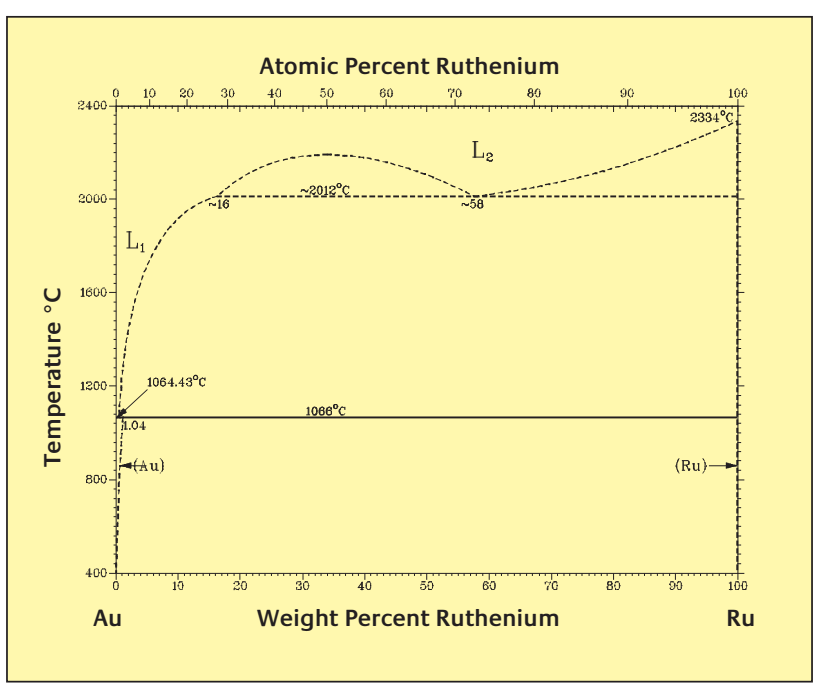

Figure 7

The Au-Ru binary alloy phase diagram (4)

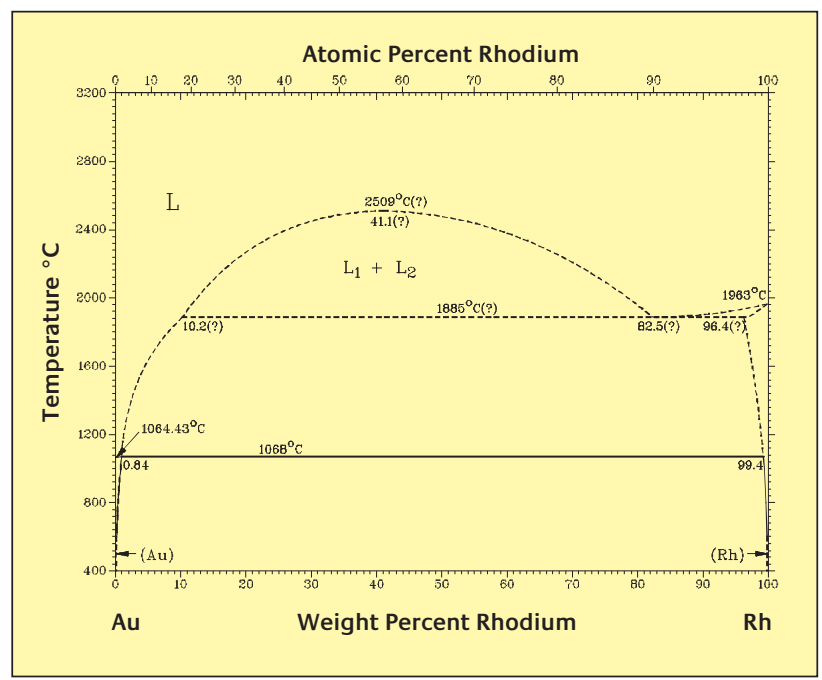

Figure 8

The Au-Rh binary alloy phase diagram (4)

distribution in the gold matrix. Comparative amounts of Pt were added to investigate its effect, well below its solubility level in gold of $\sim 15 w t \%$ (Figure 9). Knowing that any precipitation in quaternary Au-Ag-Cu-Pd/Pt alloys do not really play a role, the objective was not to induce any form of Pt-rich second phase precipitation, but to purely ascertain its effect on the hardness, regardless of the mechanism.

Pt-containing alloys can be hardened to values well in excess

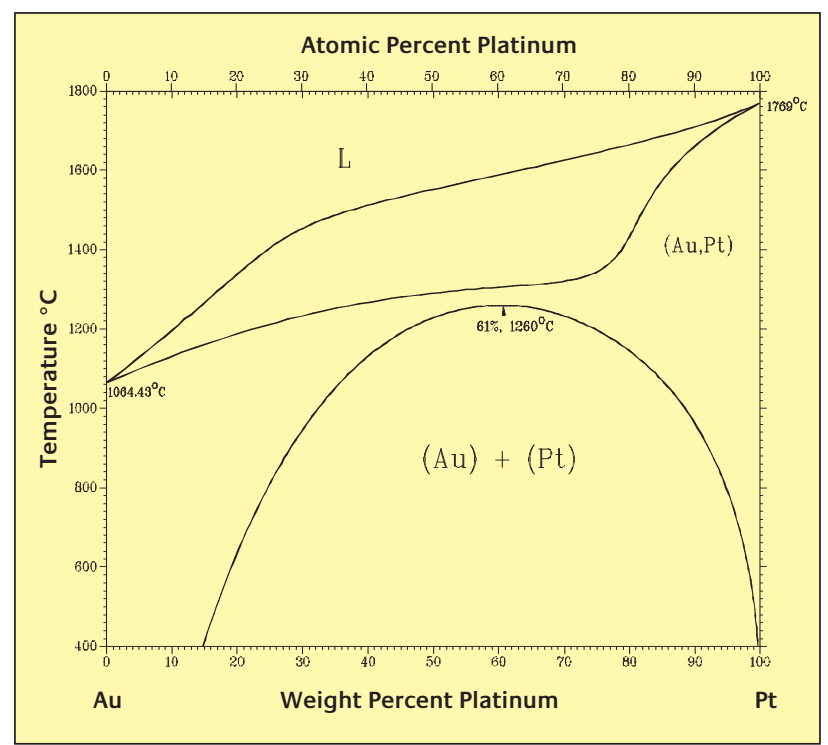

Figure 9

The Au-Pt binary alloy phase diagram (4) 
Table 4

Hardnesses of Pt-, Ru-, Rh- and Ir-containing samples in different conditions

\begin{tabular}{|c|c|c|c|}
\hline Alloy (wt\%) & Annealed @ $550^{\circ} \mathrm{C}$ & $50 \%$ Cold worked & Aged @ $300^{\circ} \mathrm{C}$ (peak hardness) \\
\hline 75Au-12.5Cu-10.5Ag-2Pt & - & $225 \mathrm{HV}$ & $300 \mathrm{HV}$ after 3 hours \\
\hline 75Au-12Cu-9Ag-4Pt & $174 \mathrm{HV}$ & $240 \mathrm{HV}$ & 333 HV after 3 hours \\
\hline 75Au-12.5Cu-10.5Ag-2Ru & $162 \mathrm{HV}$ & $239 \mathrm{HV}$ & $327 \mathrm{HV}$ after 10 hours \\
\hline 75Au-12.5Cu-10.5Ag-2Rh & $162 \mathrm{HV}$ & $241 \mathrm{HV}$ & 319 HV after 10 hours \\
\hline 75Au-12.5Cu-10.5Ag-2lr & $159 \mathrm{HV}$ & $239 \mathrm{HV}^{*}$ & $331 \mathrm{HV}$ after 10 hours \\
\hline
\end{tabular}

* $60 \%$ cold worked

of $300 \mathrm{HV}$. The alloys retained the formability associated with 18 carat gold, but were slightly bleached. The Ru/Rh/lr containing alloys on the other hand, had a rich yellow colour and excellent formability, and reached $300 \mathrm{HV}$ within 1 hour (although to reach their peak hardnesses takes 10 hours). Unfortunately, the melting point of these alloys may be unacceptably high (due to the PGM's high melting points).

However, since these alloys were promising with regard to their hardnesses, more work was done on Ru- and Ir containing alloys, with the aim of evaluating the effect of:

- alloying additions of less than $2 \mathrm{wt} \%$ on the hardness of the alloy

- Zn additions on the alloy's melting point

- further Co addition (small amounts, $1 \%$ or less) to possibly negate loss in hardness because of reduced PGM content. Easy comparisons would then be possible over a reasonably complete low percentage range of additions of either Ru or Ir. Zn and Co additions were made as well for the reasons as previously discussed. The results are shown in Table 5 .

Unfortunately, none of these additions improved on the $2 \%$ Ru/lr alloys, and did not even reach the target hardness of $300 \mathrm{HV}$. The optimum alloy of this series was the 1\% Ru alloy which reached 295 HV after 3 hours. The addition of Zn had a detrimental effect on the hardening properties of the alloy, and the additional alloying with Co did not help either. The colours of all these alloys were acceptable though, all very rich in colour. Unfortunately, most of the alloys' surfaces were marred in the polished condition by pure Ru inclusions, which embrittled the alloys. Ir did not suffer from this problem at all, but in terms of hardness it performed very similarly to Ru.

Although Ru and Ir are capable of delivering alloys with hardnesses in excess of $300 \mathrm{HV}$, investigation into Ru and Ir additions was discontinued, mainly due to the unacceptable surface finishes that were encountered. The PGM's high melting points are also a negative factor.

\section{The addition of $\mathrm{V}, \mathrm{Cr}$ and Mo}

The binary phase diagrams of Au- $\mathrm{V}, \mathrm{Au}-\mathrm{Cr}$ and Au-Mo (4) were studied. In order to induce the formation of the $\mathrm{VAu}_{4}$ phase in gold-rich $V$ containing alloys, the alloys have to contain more than approximately $5 \mathrm{wt} \% \mathrm{~V}$. Cr tends to form a solid solution with $\mathrm{Au}$ at elevated temperatures, but below $\sim 400^{\circ} \mathrm{C}, \alpha^{\prime}$ (a high $\mathrm{Cr}$ phase) may precipitate if the solubility is exceeded. The solubility of Mo in Au is extremely limited.

Table 5

Hardnesses of Pt-, Ru-, Rh-, Ir-, Zn- and Co-containing sample in different conditions

\begin{tabular}{|c|c|c|c|}
\hline Alloy (wt\%) & Annealed @ $550^{\circ} \mathrm{C}$ & Cold worked & Aged @ $300^{\circ} \mathrm{C}$ (peak hardness) \\
\hline 75Au-12.5Cu-12.5Ag-0.5Ru & $153 \mathrm{HV}$ & $218 \mathrm{HV}$ & 295 HV after 5 hours \\
\hline 75Au-12Cu-12Ag-1Ru & $100 \mathrm{HV}$ & 222 HV & 295 HV after 3 hours \\
\hline 75Au-11.75Cu-11.75Ag-1.5Ru & $150 \mathrm{HV}$ & $236 \mathrm{HV}$ & $281 \mathrm{HV}$ after 3 hours \\
\hline 75Au-10.75Cu-10.75Ag-1.5Ru-2Zn & $141 \mathrm{HV}$ & $230 \mathrm{HV}$ & 197 HV after 3 hours \\
\hline 75Au-12.5Cu-9.5Ag-0.5Ru-2.5Zn & $154 \mathrm{HV}$ & $220 \mathrm{HV}$ & $278 \mathrm{HV}$ after 5 hours \\
\hline $\begin{array}{l}\text { 75Au-11.3Cu-11.3Ag-0.8Ru- } \\
0.8 \mathrm{Zn}-0.8 \mathrm{Co}\end{array}$ & $175 \mathrm{HV}$ & $228 \mathrm{HV}$ & 266 HV after 5 hours \\
\hline $\begin{array}{l}\text { 75Au-11.2Cu-11.2Ag-0.9lr- } \\
0.8 \mathrm{Zn}-0.9 \mathrm{Co}\end{array}$ & $149 \mathrm{HV}$ & $156 \mathrm{HV}$ & 267 HV after 5 hours \\
\hline $\begin{array}{l}\text { 75Au-11.2Cu-11.2Ag-1Ir- } \\
0.8 \mathrm{Zn}-0.8 \mathrm{Co}\end{array}$ & $169 \mathrm{HV}$ & $229 \mathrm{HV}$ & $263 \mathrm{HV}$ after 5 hours \\
\hline
\end{tabular}


Additions of both 6 wt $\% \mathrm{~V}$ and 5 wt $\% \mathrm{Cr}$ bleached the colour to such an extent that the $\mathrm{V}$ containing sample had a very pale pink colour, and the $\mathrm{Cr}$ containing sample a white hue (not surprising since the bleaching ability of $\mathrm{Cr}$ has been clearly established (16)). Mo's high melting point made melting of the sample very difficult. None of these elements were found suitable for further investigation.

\section{The addition of B}

The influence of $B$ on the properties of 18 carat gold was also investigated. $\mathrm{B}$ is believed to act as a grain refiner in casting alloys, having an alleged synergetic effect together with elements like Co and Ir (11). This synergetic effect was not investigated, however, because it had already been proven. The singular addition of a non-metallic element such as B seemed to hold some promise, considering that it might also result in interstitial hardening (interstitial solid solution strengthening) (17). However, no significant alloy performance enhancement is documented when less than 300 ppm are added, and more that 300 ppm are usually not evaluated because of concern for the formation of boride hard particles, which would be detrimental to the surface finish (18). There is little known about the influence of 'excessive' $B$ additions on the hardening properties of fine gold, less so of 18 carat gold. Even the Au-B phase diagram is not that well established (Figure 11). It was therefore decided to add $\mathrm{B}$ to 18 carat gold over a wide percentage range, all in excess of 300 ppm. The results are shown in Table 6.

The results were very promising, since additions of $B$ between 400 and 3000 ppm yielded hardnesses of $290 \mathrm{HV}$ or more. All of the alloys, except for that containing 400 ppm B, reached a hardness of 300 with ageing, which reveals good ageing properties. Additions of $\sim 800 \mathrm{ppm}$ seem to be the optimum, yielding properties the same as or even better than additions as high as 3000 ppm (which seems to be on the edge of B's solubility in Au). Only TEM studies would be able to tell which hardening mechanism plays a role here.

In general, there were no problems with poor surface

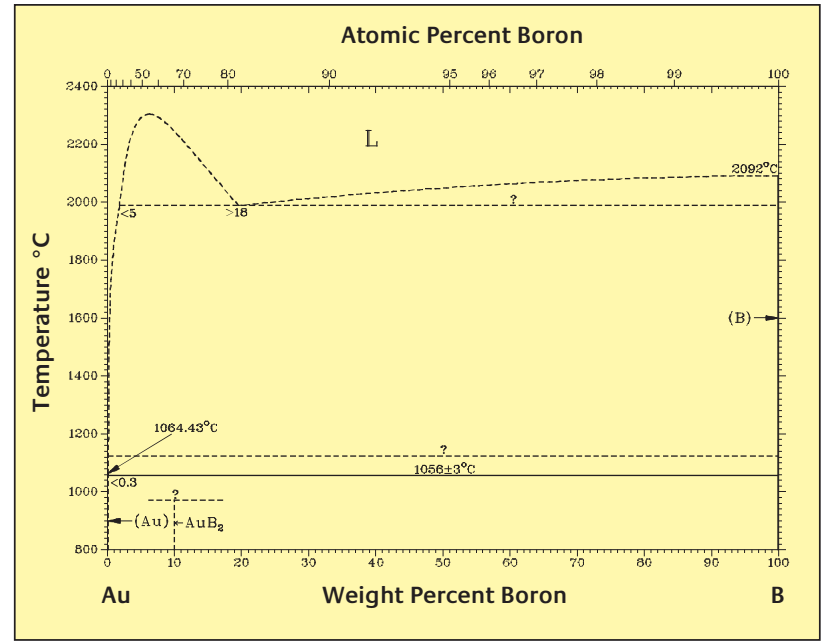

Figure 10

The Au-B binary alloy phase diagram (4)

finish due to hard inclusions, and rolling of the samples went smoothly. The colour compared very well to that of the standard 18 carat alloy in the buffed state. A very thin oxide layer (probably copper oxide) forms during melting, more severe than in the case of the standard 18 carat gold. Unlike the PGM containing alloys, the buttons produced in the arc furnace were a little bit flatter with slightly wavy textures on their surfaces due to lower surface energy.

B seemed to be a very promising alloying addition to 18 carat gold to improve its hardness.

\section{The addition of $\mathrm{Zr}$}

The addition of Zr to 18 carat gold has two potential effects: it could either change the hardness via the precipitation of $\mathrm{Au}_{4} \mathrm{Zr}$ during ageing (Figure 12), or through substitutional solid solution (17). Earlier work on the development of 990 gold showed the promise of $Z r$ at $99 w t \%$ Au level (7).

A series of alloys were made up with $\mathrm{Zr}$ additions. The colour of the alloys was not significantly affected. High levels of $\mathrm{Zr}$ (>5 wt\%) also lead to severe cracking of the samples. This was probably the result of too much $\mathrm{Au} \mathrm{Z}_{4} \mathrm{Zr}$ having

\section{Table 6}

Hardnesses of B-containing sample in different conditions

\begin{tabular}{|c|c|c|c|}
\hline Alloy (wt\%) & Annealed @ $750^{\circ} \mathrm{C}$ & $50 \%$ Cold worked & Aged @ $300^{\circ} \mathrm{C}$ (peak hardness) \\
\hline 75Au-12.47Cu-12.47Ag-0.04B & $139 \mathrm{HV}$ & $236 \mathrm{HV}^{*}$ & $284 \mathrm{HV}$ after 3 hours \\
\hline 75Au-11.46Cu-12.46Ag-0.08B & $140 \mathrm{HV}$ & $231 \mathrm{HV}$ & 302 HV after 2 hours \\
\hline 75Au-12.5Cu-12.4Ag-0.1B & $152 \mathrm{HV}$ & 219 HV & $300 \mathrm{HV}$ after 5 hours \\
\hline 75Au-12.35Cu-12.35Ag-0.3B & $156 \mathrm{HV}$ & $243 \mathrm{HV}$ & 305 HV after 3 hours \\
\hline
\end{tabular}

* $60 \%$ cold worked 


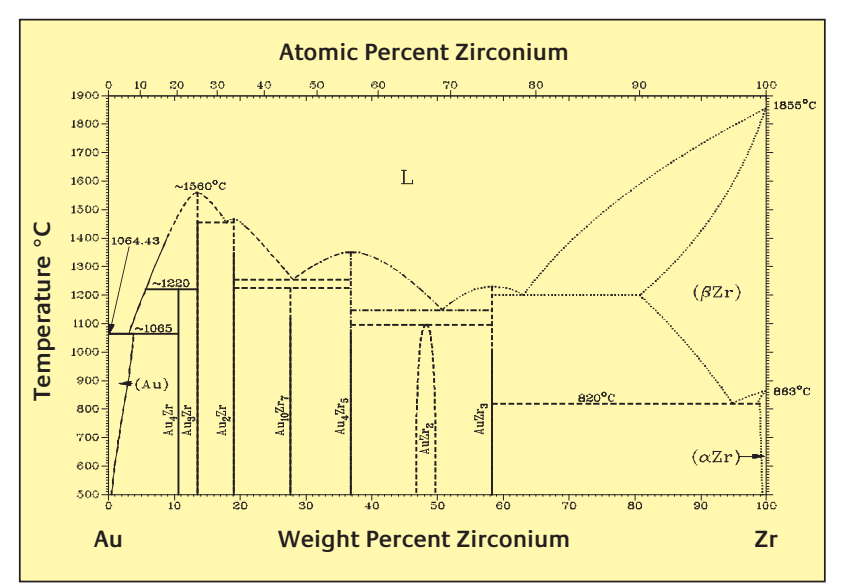

Figure 11

The Au-Zr binary alloy phase diagram (4)

formed, which would be, like most intermetallic compounds, hard and brittle. A small amount of Zr was added to hopefully form the necessary dispersion of fine second phase particles. Co was also added in combination with $\mathrm{Zr}$ for possible additional strengthening. One alloy, with composition at the edge of micro-alloying regime, was identified as having the best combination of colour, formability and hardness, and its hardening properties are shown in Table 7.

This alloy reached a hardness of over $300 \mathrm{HV}$ within 1 hour's ageing. Its annealed hardness was significantly higher than that of conventional 18 carat gold, indicating good solid solution strengthening imparted by the Zr. Although this alloy satisfied all the requirements for a hard 18 carat gold in terms of hardness, colour and formability, there was concern about castability in a jewellery workshop. The alloy formed misformed, flat and highly oxidised samples during melting. Since small amounts of silicon (0.03 wt\%) have been reported to improve alloys' fluidity and castability (19), this was attempted, but without success.

\section{The addition of $\mathrm{Al}$}

Al was successfully used in the development of Spangold, the 18 carat alloy renowned for its 'spangling' surface texture $(20,21)$. A patent also exists where $\mathrm{Al}$ is utilised in conjunction with $\mathrm{Co}$ and $\mathrm{Zn}$ (22), and Mintek wanted to investigate the merit of this approach. It was decided to only add $0.4 \mathrm{wt} \% \mathrm{Al}$ to minimise any oxidation, while $\mathrm{Zn}$ was also added to improve the alloys fluidity because initial melts proved to be unsatisfactory in this regard. Co was also added since its hardening effect has already been established in many alloys before, and replacement of Co by B was also investigated. The results are shown in Table 8.

The alloy with $12.6 \mathrm{wt} \%$ Cu seemed to be the optimum with excellent colour after grinding and polishing. Although the alloy took longer to reach 300 HV than the 14 wt\% Cu alloy, the latter alloy was too red in colour. Substituting Co with a small amount of $B$ and a large amount of $\mathrm{Zn}$ was unsuccessful. Unfortunately the samples were pitch black after melting due to the formation of an aluminium oxide, and very irregularly shaped. Even though only $0.4 \mathrm{wt} \% \mathrm{Al}$ was

\section{Table 7}

Hardnesses of Zr-and Co-containing sample in different condition

\begin{tabular}{l|l|l|l}
\hline Alloy (wt $\%)$ & Annealed @ $\mathbf{5 5 0} \mathbf{0}^{\circ} \mathbf{C}$ & $\mathbf{6 0 \%}$ Cold worked & Aged @ $\mathbf{3 0 0}{ }^{\circ} \mathbf{C}$ (peak hardness) \\
\hline $\begin{array}{l}75 \mathrm{Au}-11.5 \mathrm{Cu}-12.7 \mathrm{Ag}-0.3 \\
\mathrm{C}-0.5 \mathrm{Zr}\end{array}$ & $233 \mathrm{HV}$ & $270 \mathrm{HV}$ & $344 \mathrm{HV}$ after 10 hour \\
\hline
\end{tabular}

\section{Table 8}

Hardnesses of Al, Co and Zn containing samples in different conditions

\begin{tabular}{|c|c|c|c|}
\hline Alloy (wt\%) & Annealed @ $550^{\circ} \mathrm{C}$ & $60 \%$ Cold worked & Aged @ $300^{\circ} \mathrm{C}$ (peak hardness) \\
\hline $\begin{array}{l}\text { 75Au-11.7Cu-11.3Ag-0.8Zn- } \\
0.8 \mathrm{Co}-0.4 \mathrm{Al}\end{array}$ & $178 \mathrm{HV}$ & $242 \mathrm{HV}$ & 278 HV after 1 hour \\
\hline $\begin{array}{l}\text { 75Au-12.5Cu-10.5Ag-0.8Zn- } \\
0.8 \mathrm{Co}-0.4 \mathrm{Al}\end{array}$ & $187 \mathrm{HV}$ & $259 \mathrm{HV}$ & 305 HV after 5 hours \\
\hline $\begin{array}{l}\text { 75Au-12.6Cu-10.4Ag-0.8Zn- } \\
0.8 \mathrm{Co}-0.4 \mathrm{Al}\end{array}$ & $185 \mathrm{HV}$ & $262 \mathrm{HV}$ & 302 HV after 4 hours \\
\hline $\begin{array}{l}\text { 75Au-14Cu-9Ag-0.8Zn-0.8Co- } \\
0.4 \mathrm{Al}\end{array}$ & $168 \mathrm{HV}$ & $151 \mathrm{HV}$ & $311 \mathrm{HV}$ after 5 hours \\
\hline $\begin{array}{l}\text { 75Au-11.4Cu-11.4Ag-1Zn- } \\
0.8 \mathrm{Co}-0.4 \mathrm{Al}\end{array}$ & $122 \mathrm{HV}$ & $237 \mathrm{HV}$ & $273 \mathrm{HV}$ after 5 hours \\
\hline $\begin{array}{l}\text { 75Au-11.5Cu-11.5Ag-1.52Zn- } \\
0.08 \mathrm{~B}-0.4 \mathrm{Al}\end{array}$ & $143 \mathrm{HV}$ & $242 \mathrm{HV}$ & 270 HV after 2 hours \\
\hline
\end{tabular}


added, oxidation still remained a problem. Meltability of the alloy remained problematic even with zinc added, which would render the alloy difficult to cast.

\section{The most promising alloys}

Table 9 gives the chemical compositions of nine 18 carat alloys with good formability and colour that can be hardened to a value in excess of $300 \mathrm{HV}$.

Alloys 1 to 4 in Table 9 were chosen for further evaluation. Although the alloys containing PGMs were also very promising as 18 carat hard gold alloys, their high melting points and price made them less attractive options. Regardless of the fact that it was suspected that the Zr- and Al-containing alloys might not behave well during investment casting, it was decided to test them further. Figure 4 shows

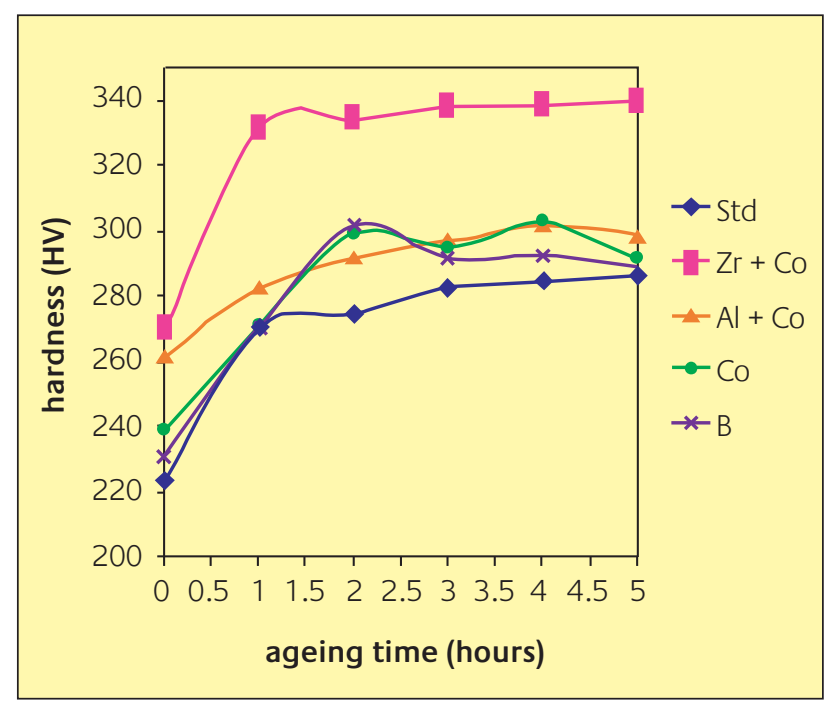

Figure 12

The change in hardness of 18 carat alloys during ageing at $300^{\circ} \mathrm{C}$

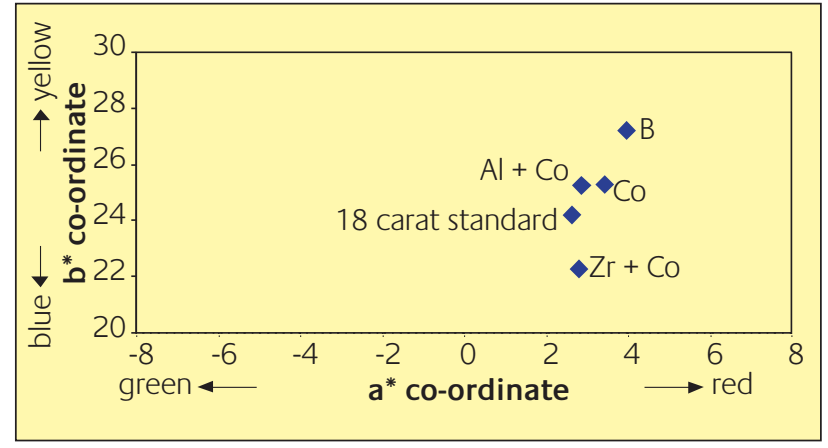

\section{Figure 13}

The CIElab colour co-ordinates of the experimental alloys compared to those of conventional 18 carat gold

the ageing behaviour of Alloys 1-4 compared against that of the standard 18 carat alloy, where the 0 hour ageing time is actually the $50-60 \%$ cold worked condition. The graph is very illustrative of how the novel 18 carat alloys can be made harder than the conventional 18 carat alloy (the lowest curve on the graph). Even the cold worked hardness of the experimental alloys was higher. The $\mathrm{Zr}+\mathrm{Co}$-containing alloy stands out for its exceptional age-hardening properties. It reached its peak hardness of $330 \mathrm{HV}$ within an hour compared to the B- and Co-containing alloys which reached hardness values of $300 \mathrm{HV}$ in 2 hours, while the $\mathrm{Al}+\mathrm{Co}$ alloy only reached it in 3 hours. All these ageing times are, however, acceptable.

Figure 5 compares the CIELab colour co-ordinates of the experimental alloys to those of conventional 18 carat gold. Considering that a deviation in $\mathrm{a}^{*}$ and/or $\mathrm{b}^{*}$ co-ordinates of value 1 is defined to be the 'resolution' of the human eye, the $\mathrm{Co}$ and $\mathrm{Al}+\mathrm{Co}$-containing alloys were very similar in colour than that of the standard 18 carat. Although the deviation for the other two alloys were larger, their colours were judged to be good as well.

\section{Table 9}

The chemical compositions (wt\%) of the 18 carat alloys, 75 weight per cent gold, that can be hardened to a value in excess of 300 points on the vickers scale

\begin{tabular}{lllllllll} 
Alloy & $\mathbf{A g}$ & $\mathrm{Cu}$ & $\mathrm{Zr}$ & Co & PGM & B & Zn & Al \\
\hline 1 & 12.7 & 11.5 & 0.5 & 0.3 & - & - & - & - \\
\hline 2 & 10.4 & 12.6 & - & 0.8 & - & - & 0.8 & 0.4 \\
\hline 3 & 12.0 & 12.0 & - & 1.0 & - & - & - & - \\
\hline 4 & 12.46 & 12.46 & - & - & - & 0.08 & - & - \\
\hline 5 & 12.0 & 9.0 & - & - & $4.0 \mathrm{Pt}$ & - & - & - \\
\hline 6 & 12.5 & 10.5 & - & - & $2.0 \mathrm{Pt}$ & - & - & - \\
\hline 7 & 10.5 & 12.5 & - & - & $2.0 \mathrm{Ru}$ & - & - & - \\
\hline 8 & 10.5 & 12.5 & - & - & $2.0 \mathrm{Rh}$ & - & - & - \\
\hline 9 & 10.5 & 12.5 & - & - & $2.0 \mathrm{Ir}$ & - & - & - \\
\hline
\end{tabular}




\section{Casting}

Since gold jewellery is primarily investment cast, it was important to know whether these experimental alloys could be successfully cast in terms of proper form filling, minimal defects in the cast item, and no adverse reactions of the alloy with the investment.

To evaluate the form filling properties of the alloys, specimens of a fixed geometry, the grid pattern depicted in Figure 6 , were cast. Performance could be evaluated based on the amount of grid area filled by the cast metal.

The Co- and B-containing alloys were melted by gas flame in an alumina crucible, while the Al- and Zr-containing alloy were induction-melted in graphite crucibles. The alloys were then centrifugally investment cast. After casting, the cast items were cooled in air, and the bulk of the investment wax was washed off in water, after which the castings were sand blasted to free them of the remaining investment material as well as the bulk of the oxidation layer.

The form filling properties of all the alloys (including, surprisingly, the Al- and Zr-containing alloys) were excellent, the respective grids being completely filled in all dimensions. Figure 6 shows each of the standard form fill test grids.

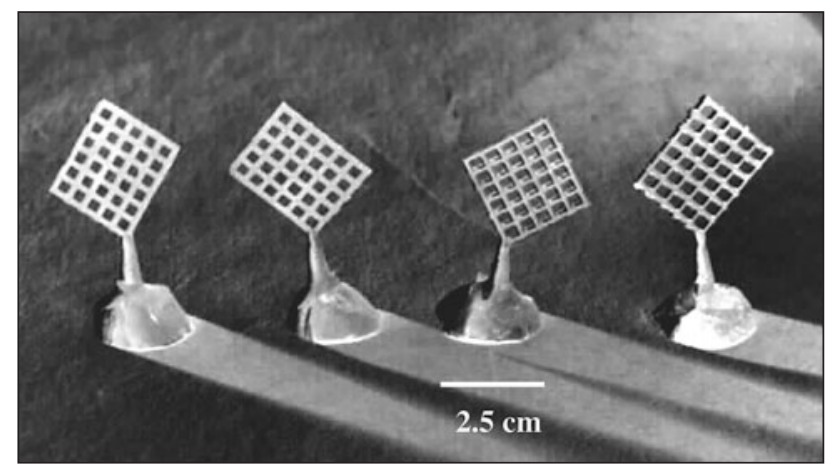

Figure 14

Standard form fill test grids. From left to right: alloys containing Co, B, $\mathrm{Al}+\mathrm{CO}$ and $\mathrm{Zr}+\mathrm{CO}$

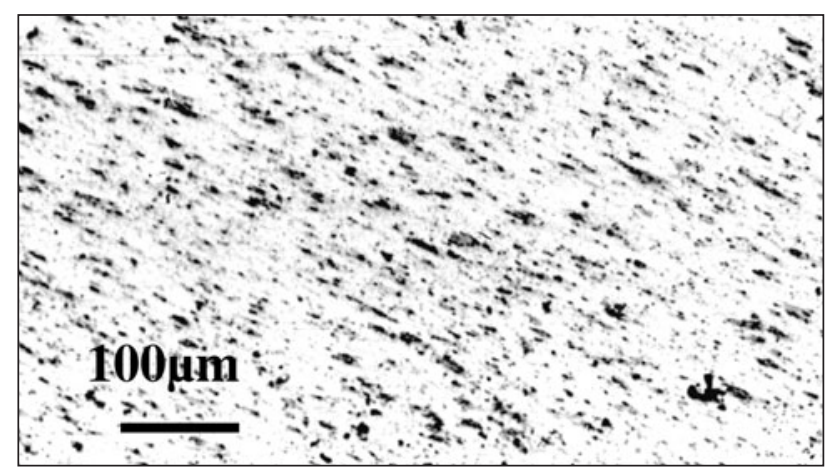

Figure 15

Metallographic section of the as-cast grid of the Co-containing alloy. The B-containing alloy was similar in appearance
The grids were ground and polished to a $6 \mu \mathrm{m}$ finish, and metallographically examined by optical microscopy (Figure 15).

Figure 7 is representative of both the Co- and B-containing alloys, showing fine, homogeneously distributed, irregularly shaped porosity, probably interdendritic in most instances, or even a combination of shrinkage and gas effects (23). Large localised porosity were very visible on the polished surface of the grids.

Possible reaction of the alloys with the graphite or alumina crucibles during melting was a concern, but microprobe-EDS analysis of the cast items proved that there had been no pickup of aluminium, carbon or oxygen during the entire casting process.

If a choice has to be made in terms of casting properties, the Co- and B-containing alloys would be more favourable, because they had less macro-porosity than the other two alloys.

The only significant conclusions that could be drawn from the results of these preliminary casting trials were that none of the alloys presented any problems with filling of the mould, but that there was too much porosity in the cast items. It has to be said that the casting conditions had not been optimised. More substantial investment casting trials are needed to evaluate suitability for conventional tree set-up and tree sizes.

\section{Corrosion testing}

The corrosion resistance of the alloys was evaluated by exposing the samples to three different corrosive media: artificial perspiration $(0.75 \mathrm{~g} \mathrm{NaCl} ; 0.12 \mathrm{~g} \mathrm{KCl} ; 0.27 \mathrm{ml}$ lactic acid; $0.1 \mathrm{~g}$ urea; up to $100 \mathrm{ml}$ water); sea water $(3.56 \% \mathrm{NaCl})$ and dilute sulphuric acid ( $1 \mathrm{M} \mathrm{H}_{2} \mathrm{SO}_{4}$ ). The testing in artificial perspiration is probably the most important, because it gives an indication of whether the alloy would be resistant to perspiration during everyday wear. The other two tests evaluated resistance to chloride containing and acidic environments.

The alloys were exposed to the respective solutions for a period of 7 weeks, after which the weight loss was calculated and compared to that of the standard. It was expected that the standard 18 carat alloy would show no significant weight loss, as was indeed the case. The experimental alloys did not show any weight loss either. It can be concluded that the corrosion resistance of the experimental alloys is very similar to that of the standard 18 carat alloy.

\section{Conclusion}

In terms of hardness, nine alloys were described that were harder (300 HV obtainable) 18 carat yellow gold, with colour that compared well to that of the standard 18 carat (3N) alloy. However, some of these alloys contained PGMs 
which, although they induce good hardening of the alloys, have high melting points and do not always go into solution. Alloys containing $\mathrm{Co}, \mathrm{B}, \mathrm{Al}$ and $\mathrm{Zr}$ were therefore preferred. Very preliminary casting trials have indicated good flow properties. The $\mathrm{Zr}$ - and $\mathrm{Al}+\mathrm{Co}$ containing alloys, although conforming to the colour and hardness requirements as originally set out, were not as promising as the Co- and B-containing alloys. The latter two alloys showed the least amount of problems during the development stage in terms of melting, oxidation at elevated temperatures and porosity. The (in part) high reactivity of some of the alloying additions need not be a problem during casting or melting because protective gases or fluxes, which are freely available, can be used to eliminate high temperature surface oxidation. It has to be acknowledged that problems could arise during continuous casting for fabrication of semi-finished products in the watch and jewellery industry.

To summarise, these 18 carat hard alloys could have the following benefits in the jewellery and/or watch industry:

- The colours of the experimental alloys compare well with the colour of conventional 18 carat yellow gold.

- The heat treatment cycle required to harden the alloys is similar to that prescribed for hardening the conventional 18 carat Au-Cu-Ag alloys.

- The maximum hardness that can be obtained is well within the range required by watch manufacturers for watch case production. The resulting watch cases would probably be easier to machine and have good wear properties.

- The hardness of the alloys in the annealed condition compares well with that of the white gold alloys currently used to manufacture clasps, while still being formable (the alloys were successfully cold rolled down to $60 \%$ reduction without cracking).

- From an aesthetic point of view, the experimental alloys with their yellow colour are more suitable for use in clasps, especially when the clasp is to be used in combination with a yellow 18 carat gold jewellery piece. Manufacturing of the jewellery pieces, especially soldering, will be considerably easier if the colour of the clasp matches that of the jewellery item.

- The alloys contain no alloying elements known to increase the risk of skin allergies.

- These preferred alloys are all corrosion resistant.

The alloys have the potential to be well suited for jewellery applications particularly those in which a high strength is required. However, there are specific practical issues that need to be addressed to properly evaluate suitability for jewellery or watch manufacture. This would include:

- more substantial investment casting trials

- investigation of age-hardening properties in the as-cast state
- continuous casting trials

- investigation of general melting and working properties using larger quantities of material

- soldering properties of the alloys

- machinability of the alloys.

In addition, it would also be important to determine the relevant hardening mechanism involved for every alloying addition. This would involve some TEM studies.

\section{Acknowledgement}

This paper is published by permission of Mintek.

\section{About the Authors}

Mr Rainer Süss is a senior engineer in the Advanced Materials Group, Physical Metallurgy Division, Mintek, and has been involved with the development of novel gold alloys for the jewellery industry. Currently, he is primarily involved with research and development of platinum alloys for industrial applications.

Dr Elma van der Lingen heads the Precious Metals Group, Physical Metallurgy Division, Mintek, which is involved in the chemistry, physics, metallurgical and especially catalytic properties of gold.

Prof Madeleine du Toit teaches and conducts research in the fields of physical metallurgy and welding engineering in the Department of Materials Science and Metallurgical Engineering at the University of Pretoria. Previously, at Mintek, she specialised in the metallurgy of gold alloys.

Lizelle Glaner is a Senior Technician in the Advanced Materials Group and is involved in precious metals research.

\section{References}

1 Gold 2000, Gold Fields Mineral Services, Ltd

2 Gold alloy data, Gold Technol., 1990, 1

3 J.C. Chaston, Gold Bull., 4(4), 1971, 70

4 Binary Alloy Phase Diagrams, 2nd edition, Ohio, USA, Amer. Soc. Metals. 1990

5 K. Yasuda, Gold Bull., 20(4), 1987, 90

6 A.S. McDonald and G.H. Sistare, Gold Bull., 11(3), 1978, 66

7 C.W. Corti, Gold Bull., 32(2), 1999, 39

8 M. du Toit, Elma van der Lingen, L. Glaner and R. Süss, Gold Bull., 35(2), 2002

9 R. Süss, E. van der Lingen, M. du Toit, C. Cretu and L. Glaner, Proceedings of Gold 2003: New industrial applications for gold, Vancouver, Canada, 28 September - 1 October 2003

10 D. Ott, Gold Technol., 1997, 22, 31 
12 J. Fischer-Bühner, Proceedings of Gold 2003: New industrial applications for gold, Vancouver, Canada, 28 September - 1 October 2003

13 G. Gafner, Gold Bull., 22(4), 1989, 112-122

14 T. Tani, K. Udoh, K. Yasuda, G. van Tendeloo and J. van Landuyt, J. of Dental Research, 70(10), 1991, 1350

15 K. Yasuda and M. Ohta, J. Less-Comm. Met., 70(2), 1980, 75

16 J. Fischer-Bühner, Proceedings of the Santa Fe Symposium on Jewelry Manufacturing Technology, 2001, 131

17 S.H. Avner, 1974. Introduction to Physical Metallurgy. 2nd ed., McGrawHill. pp. 132, 153
18 G. Normandeau, Proceedings of the Santa Fe Symposium on Jewelry Manufacturing Technology, 1996, 83

19 G. Normandeau and R. Roeterink, Gold Tech., 15, 1995, 4

20 M. Wolff and M.B. Cortie, Gold Bull., 1994, 27, 45

21 M. Cortie, I. Wolff, F. Levey, S. Taylor, R. Watt, R. Pretorius, T. Biggs and J. Hurly, Gold Technol., 1994, 4, 30

22 Japanese Patent 8013060: The Pilot Corp, 26 June 1994.

23 R.E Reed-Hill and R. Abbaschian, R. 1994. Physical Metallurgy Principles. 3rd ed., PWS Publishing. pp. 471, 470, 518

Continued from Maye et al p223

Dr. C.J. Zhong is an associate professor of Chemistry at SUNY. His research is in the interdisciplinary fields of analytical, materials, electrochemistry and nanotechnology. His recent work on nanoparticles and nanostructures is aimed at developing advanced materials and technologies for fuel cells, sensors and biosensors.

\section{References}

1 X.M. Ren, P. Zelenay, S. Thomas, J. Davey, S. Gottesfeld, J. Power Sources, 2000, 86, 111

2 D. Chu, R. Jiang, Solid State Ionics, 2002, 148, 591

3 U.A. Paulus, U. Endruschat, G.J. Feldmeyer, T.J. Schmidt, H. Bonnemann, R.J. Behm, J. Catal., 2000, 195, 383

4 E. Antolini, Mater. Chem. Phys., 2003, 78, 563

5 G.Q. Lu, A. Wieckowski, Curr. Opin. Coll. Interf. Sci., 2000, 5, 95

6 L. Xiong, A.M. Kannan, A. Manthiram, Electrochem. Commun., 2002, 4, 898

7 M. Haruta, Catal. Today, 1997, 36, 153

8 M. Haruta, M. Date, Appl. Catal. A, 2001, 222, 427

9 G.C. Bond, D.T. Thompson, Gold Bull., 2000, 33, 41

10 G.C. Bond, Gold Bull., 2001, 34, 117

11 C.W. Corti, R.J. Holliday, D.T. Thompson, Gold Bull., 2002, 35, 111

12 A. Ueda, M. Haruta, Gold Bull., 1999, 32, 3

13 D. Andreeva, Gold Bull., 2002, 35, 82

14 R. Grisel, K.J. Weststrate, A. Gluhoi, B.E. Nieuwenhuys, Gold Bull., 2002, 35,39

15 D.T. Thompson, Gold Bull., 1998, 31, 111 \& 1999, 32, 12

16 L.D. Burke, P.F. Nugent, Gold Bull., 1998, 31, 39

17 C.J. Zhong, M.M. Maye, Adv. Mater., 2001, 13, 1507

18 Gold 2003: New Industrial Applications for Gold, Proceeding Volume, World Gold Council, 2003

19 D. Cameron, R. Holliday, D. Thompson, J. Power Sources, 2003, 118, 298

20 Y. Lou, M.M. Maye, L. Han, J. Luo, C.J. Zhong, Chem. Commun., 2001, 473
21 J. Luo, M.M. Maye, Y. Lou, L. Han, M. Hepel, C.J. Zhong, Catal. Today, 2002, 77, 127

22 J. Luo, Y.B. Lou, M.M. Maye, C.J. Zhong, M. Hepel, Electrochem. Comm., 2001, 3, 172

23 J. Luo, V.W. Jones, M.M. Maye, L. Han, N.N. Kariuki, C.J. Zhong, J. Am. Chem. Soc., 2002, 124, 13988

24 M.M. Maye, J. Luo, Y. Lin, M.H. Engelhard, M. Hepel, C.J. Zhong, Langmuir, 2003, 19, 125

25 M.M. Maye, J. Luo, L. Han, N. Kariuki, C.J. Zhong, Gold Bull., 2003, 36, 75

26 C.J. Zhong, M.M. Maye, J. Luo, L. Han, N.N. Kariuki, in "Nanoparticles: Building Blocks for Nanotechnology", Ed. By V.M. Rotello, Kluwer Academic Publishers. Chapter 5, pp.113-144, 2004

27 C.J. Zhong, J. Luo, M.M. Maye, L. Han, N.N. Kariuki, in "Nanotechnology in Catalysis", Ed. By B. Zhou, S. Hermans, G.A. Somorjai, Kluwer Academic/Plenum Publishers. Vol. 1., Chapter 11, pp. 222-248, 2004

28 Y.D. Kim, M. Fischer, G. Gantefor, Chem. Phys. Lett., 2003, 377, 170

29 Y. Xu, M. Mavrikakis, J. Phys. Chem. B, 2003, 107, 9298

30 M.V. Brussel, G. Kokkinidis, I. Vandendael, C. Buess-Herman, Electrochem. Commun., 2002, 4, 808

31 M.S. El-Deab, T. Ohsaka, Electrochim. Acta, 2002, 47, 4255

32 M. Brust, M. Walker, D. Bethell, D.J. Schiffrin, R. Whyman, J. Chem. Soc., Chem. Commun. 1994, 801

33 M.M. Maye, W.X. Zheng, F.L. Leibowitz, N.K. Ly, C.J. Zhong, Langmuir, 2000, 16, 490

34 M.M. Maye, C.J. Zhong, J. Mater. Chem., 2000, 10, 1895

35 M.J. Hostetler, C.J. Zhong, B.K.H. Yen, J. Anderegg, S.M. Gross, N.D. Evans, M.D. Porter, R.W. Murray, J. Amer. Chem. Soc., 1998, 120, 9396

36 M.J. Hostetler, J.E. Wingate, C.J. Zhong, J.E. Harris, R.W. Vachet, M.R. Clark, J.D. Londono, S.J. Green, J.J. Stokes, G.D. Wignall, G.L. Glish, M.D. Porter, N.D. Evans, R.W. Murray, Langmuir, 1998, 14, 17

37 U.A. Paulus, A. Wokaun, G.G. Scherer, T.J. Schmidt, V. Stamenkovic, V. Radmilovic, N.M. Markovic, P.N. Ross, J. Phys. Chem. B, 2002, 106, 4181

38 "Catalysis by Metals and Alloys", Ed. By V. Ponec V and G.C. Bond, Elsevier, 1995 